\title{
Desempenho Social de Pré-escolares em Situações Estruturadas: Estimativas de Mães e Professoras
}

\author{
Talita Pereira Dias ${ }^{1}$ \\ Zilda Aparecida Pereira Del Prette \\ Almir Del Prette \\ Universidade de São Carlos
}

\begin{abstract}
RESUMO - Identificar variáveis que influenciam a avaliação de comportamento infantil tem implicações para diagnóstico e intervenção psicológica. Buscou-se avaliar a estimativa de mães e professoras sobre desempenho social de crianças com e sem comportamentos-problema em cinco situações sociais estruturadas, analisando convergências e divergências (subestimações e superestimações) entre informantes e entre estimativa dos informantes e desempenho apresentado, além de diferenças entre situações nesses indicadores. Participaram 26 crianças de quatro grupos: com comportamentos-problema internalizantes (CPI), externalizantes (CPE), mistos (CPM) e com habilidades sociais (CHS). Os resultados indicaram: maior convergência para o grupo CHS; maior divergência tipo subestimação para o CPI e para situação Defende seus próprios direitos, bem como superestimação no CPM. São discutidas implicações para pesquisa, prática clínica e educacional na Psicologia.
\end{abstract}

Palavras chaves: competência social, distúrbios de comportamento, estimativa, métodos de observação, pré-escolares

\section{Social Performance's Preschoolers in Structured Situations: Estimation of Mothers and Teachers}

\begin{abstract}
Identifying variables that may influence the evaluation of behaviors in children has implication to diagnostic and psychological intervention. This study focused the mothers' and teachers' estimative about the social performance displayed by children with, and without behavior problems in five structured social situations, analyzing convergences and divergences (underestimation and overestimation) between informants and between estimative of informants and recorded performance, besides differences among situations in relation to indicators. Twenty-six children were divided into four groups: internalizing behavior problems (CPI), externalizing (CPE), mixed (CPM), and with social skills (CHS). The results indicated: more convergence to CHS group; more divergence associated with underestimation to CPI and to situation of defending one's own rights, as also overestimation to CPM group. Implications to research, clinical, and educational practices were discussed.
\end{abstract}

Keywords: social competence, behavior disorders, estimation, observation methods, preschoolers

A avaliação dos comportamentos e características das pessoas pode ser realizada por meio de método direto e indireto. No campo de Habilidades Sociais, o método indireto, sob a forma de escalas e inventários, é o mais adotado, principalmente na avaliação de crianças (Del Prette, Monjas-Casares, \& Caballo, 2006). Conforme Del Prette e Del Prette (2006), os dados obtidos por escalas e inventários representam uma estimativa feita pelo avaliador com base na amostra de observações de comportamentos do avaliado a que tem acesso. Essa estimativa pode oferecer indícios dos critérios desse avaliador sobre a funcionalidade de determinados comportamentos em ambientes específicos e, portanto, da probabilidade de serem mantidos pelos agentes significantes desse ambiente. A avaliação via relato pode ser influenciada por distorções ou vieses da percepção dos avaliadores. Isso pode ser mais acentuado quando o indivíduo avaliado apresenta algum transtorno psicológico, especialmente problemas de comportamento, o

1 Endereço para correspondência: Praça João Birolli, 134, Centro, Uchoa SP, Brasil. CEP: 15890-000 CEP E-mail. talitapsi10@yahoo.com.br que pode induzir os avaliadores a atribuírem características referidas nos critérios diagnósticos que podem nem ser de fato observadas (Silva, 2000). O termo problemas de comportamento é enfocado nos manuais médicos, como DSM-IV (2002) ou CID-10 (OMS, 1993), sob a forma de transtornos como: desafiador opositivo, de conduta, de comportamento disruptivo sem outra especificação, misto de conduta e emoções e de conduta depressiva. Os problemas de comportamento podem ter muitos indicadores, incluindo os comportamentos indesejáveis, disruptivos, problemáticos, mas também de ansiedade, obsessões, medo, sintomas depressivos.

Muitas vezes os termos problemas de comportamento e comportamentos problema ou problemáticos são utilizados com significados semelhantes, mesmo quando não se dispõe de diagnóstico preciso. Neste texto, o termo, no entanto, será entendido como categoria descritiva para todo e qualquer comportamento social que bloqueia ou dificulta a ocorrência de comportamentos das classes de habilidades sociais e consequentemente, comprometem a competência social. Essa opção tem o propósito de (a) ressaltar que não é o 
organismo que tem problemas, mas são os comportamentos que podem ser classificados dessa forma; (b) evitar qualquer relação com quadros nosológicos descritos em manuais psiquiátricos, como CID ou DSM, embasados em modelo médico e sintomático.

Alguns estudos constataram uma avaliação enviesada de informantes em relação a crianças com comportamentos problemáticos. Os estudos de Bolsoni-Silva, Marturano, Pereira e Manfrinato (2006) e Bolsoni-Silva, Marturano e Manfrinato (2005), com pré-escolares mostraram que: (a) professoras atribuíam escores mais altos de problemas de comportamento (termo usado pelos autores do estudo) e mais baixos de habilidades sociais do que as mães, para crianças do grupo com problemas de comportamentos; (b) mães de crianças com indicação escolar de problemas de comportamento atribuíam maior frequência de problemas de comportamento para seus filhos do que as mães de crianças com comportamentos desejáveis. As diferenças encontradas em estudos desse tipo sugerem a influência de diferentes variáveis tais como critérios diferenciados de avaliadores, variáveis pessoais do avaliado - como presença de diagnóstico de problemas de comportamento (BolsoniSilva et al., 2006; Gresham, Lane, MacMillan, Bocian, \&Ward , 2000), idade, sexo, religião - e do avaliador - como quantidade de contato, tipo de contexto de interação(Gresham \& Elliott, 2008) idade, sexo, religião, etc.

Os vieses de avaliação, associados a essas variáveis podem ser minimizados, dependendo dos métodos adotados. Os métodos diretos produzem dados objetivos importantes que, além de complementar os dados de relato e reduzir possíveis vieses, possibilitam um acesso mais amplo a diferentes indicadores de competência social (verbais, não verbais e paralinguísticos) e também às contingências imediatas sob as quais ocorrem (Del Prette \& Del Prette, 2006). Dadas as dificuldades da observação em ambiente natural, a observação direta em situações estruturadas tem sido considerada uma alternativa viável na avaliação de competência social (Bandeira, Barroso, Reis, Gaspar, \& Silva, 2004; Bandeira, Barroso, \& Reis, 2004; Del Prette \& Pereira, 2008; Ferreira, Del Prette, \& Lopes, 2009; GarciaSerpa, Del Prette, \& Del Prette, 2006; Pavarino, Del Prette,\& Del Prette, 2005). Situações estruturadas consistem em um arranjo de condições ambientais, planejadas de modo a gerar demandas para um desempenho social, que pode ser crítico para a qualidade das relações, mas que pode ocorrer com baixa frequência em situação natural (Del Prette \& Del Prette, 2006).

Quando se considera a multidimensionalidade das habilidades sociais (dimensões pessoal, situacional e cultural) justifica-se um delineamento de avaliação multimodal que assegure maior completude e confiabilidade aos resultados obtidos (Del Prette \& Del Prette, 2005a, 2006, 2009). Não obstante o campo de habilidades sociais dispor de variados recursos para a avaliação multimodal (Del Prette \& Del Prette, 2006, 2009), ainda são raros os estudos que adotam diferentes métodos, em particular, estudos que incluem a observação direta. Essa escassez de investigação com delineamento semelhante pode estar relacionada aos às dificuldades da articulação de diferentes procedimentos e ao tempo despendido nesse processo (Del Prette \& Del Prette, 2009).

No Brasil, estudos que envolvam a avaliação multimodal de habilidades sociais de crianças são feitos, em particular envolvendo a comparação de dados obtidos por método direto e indireto. Em geral, há apenas o uso de diferentes informantes (p. ex., Barreto, Freitas, \& Del Prette, 2011; Feitosa, 2003; Freitas \& Del Prette, 2010; Del Prette, Del Prette, Oliveira, Gresham, \& Vance, 2012), ainda assim poucos conduzidos com a população pré-escolar (por exemplo, Bolsoni-Silva et al., 2006; Leme \& Bolsoni-Silva, 2010). Estudos de outros países que correlacionaram dados de relato e observação de comportamento de pré-escolares indicaram que: (a) em situações naturais, no ambiente escolar, pais estimam de forma mais precisa os comportamentos internalizantes e professoras os externalizantes das crianças (Hinshaw, Han, Erhardt,\& Huber 1992); (b) baixa correlação entre os informantes para a avaliação das habilidades sociais e correlações baixas e moderadas, respectivamente, para a avaliação de comportamentos internalizantes e externalizantes (Winsler \& Wallace, 2002); (c) em observações naturais em salas de aulas, a avaliação dos professores estásignificativamente mais relacionada aos dados de observação do que às estimativas dos pais (Winsler \& Wallace, 2002).

Quando a avaliação é feita com amostra de crianças com indicativos de comportamentos-problema, as possíveis razões para a pouca acurácia entre as avaliações podem se tornar ainda mais complexas. Pode-se supor, por exemplo, que a baixa qualidade de suas interações com adultos (avaliadores) enviesaria a avaliação dos informantes, que tenderiam a superestimar os comportamentos-problema e a subestimar as habilidades sociais. Isso pode ter importância prática e implicações diretas no desenvolvimento das crianças, uma vez que essa possível divergência ou viés do avaliador dificultaria o manejo eficiente de contingências favoráveis à promoção de repertórios mais adaptativos, na medida em que este provavelmente estaria menos atento aos comportamentos adequados das crianças.

A análise da qualidade das avaliações feitas pelos informantes pode também ser muito útil na condução do processo terapêutico, uma vez que, se pais e professores são bons observadores e conseguem estimar e relatar o que as crianças fazem no contexto natural, essas informações os auxiliarão a prever se e quanta generalização está ocorrendo para os diferentes contextos, quais antecedentes favorecem a emissão dos comportamentos-problema e quais os comportamentos apresentados. Por outro lado, se os informantes apresentam dificuldades na observação ou relatos enviesados dos comportamentos das crianças. Essas distorções deveriam ser também alvo da intervenção do psicoterapeuta, que poderia planejar procedimentos para melhorar a acurácia das observações ou dos relatos dos informantes e principais agentes de socialização da criança.

Portanto, investigar as convergências e divergências dos dados de relato de pais e professores com dados de observação direta do desempenho pode trazer informações relevantes para o refinamento de diagnósticos confiáveis e consequentemente contribuir no desenvolvimento de recursos e técnicas educativas e/ou terapêuticas mais eficazes. Adicionalmente, essas investigações poderiam justificar 
intervenções visando aprimorar as habilidades de observação de professores e pais, tanto dos recursos comportamentais das crianças (repertório de habilidades sociais), quanto de comportamentos-problema (prática de bullying, esquiva diante de normas etc.).

As considerações anteriores estão na base do presente estudo que teve como objetivo analisar a estimativa de mães e professoras sobre o desempenho social apresentado por crianças com e sem comportamentos-problema em cinco diferentes situações estruturadas de interação social, comparando convergências e divergências entre informantes e entre estimativa dos informantes e desempenho registrado, além de diferenças entre as situações quanto a esses indicadores.

\section{Método}

Esta pesquisa foi aprovada pelo Comitê de Ética da Universidade Federal de São Carlos (CEP/UFSCar, processo no. 330/2008), seguindo as normas da Resolução CNS 196/96 sobre pesquisa com seres humanos.

\section{Participantes}

Participaram 26 crianças, suas mães e respectivas professoras. As crianças foram selecionadas a partir de uma amostra mais ampla avaliada pelas mães e professoras, por meio da Escala de Comportamentos Sociais para Pré-Escolares (PKBS-BR, Merrell, 2002, em processo de validação preliminar no Brasil por Dias, Freitas, Del Prette e Del Prette (2011). Foram formados quatro grupos com base na combinação de escores de habilidades sociais e comportamentos-problema: CHS, com repertório de habilidades sociais (escore alto na escala de habilidades sociais e baixo em ambas subescalas de comportamentosproblema); CPI, com escore baixo para habilidades sociais e alto para comportamentos-problema internalizantes; CPE, com escores baixos em habilidades sociais e altos para comportamentos externalizantes; CPM, ou misto, com escores baixos de habilidades sociais e alto para comportamentos-problema externalizantes e internalizantes. Além das 26 crianças, quatro meninas e dois meninos, entre cinco e seis anos, participaram como colaboradores na composição das situações estruturadas.

Participaram, ainda, 22 mães (uma delas com dois filhos participantes), três avós e 14 professoras, todas do sexo feminino. A idade das mães variou entre 24 e 43 anos (média de 32,42; $d p=4,9$ ), e as três avós (que serão referidas como mães) tinham entre 40 e 55 anos. O nível socioeconômico, obtido por meio do Critério de Classificação Econômica Brasil (ABEP, 2003), variou de B1 a D e a maioria concentrou-se nas classes $\mathrm{C}$ e D. A idade das professoras variou entre 27 e 46 anos (idade média $=34,64 ; d p=6,16$ ) e o nível socioeconômico de $\mathrm{A} 2 \mathrm{a} \mathrm{C}$, com tempo de magistério de 6 a 10 anos.

\section{Instrumentos, Materiais e Equipamentos}

Roteiro de Entrevista sobre Desempenho Social para Mães e Professoras. Conjunto de perguntas padronizadas elaboradas para este estudo sobre como a criança teria agido nas diferentes situações estruturadas,por exemplo: Então, o que você acha que [nome da criança] fez nesta situação? Se não especificadas as reações, perguntava-se Como você acha que ele vai fazer isso? O que ele falou ou fez?

Lista de Opções de Desempenho Social Infantil para Informantes. Texto com a descrição de opções de comportamentos sociais que as crianças poderiam apresentar na situação, disponibilizado aos informantes, durante a entrevista. Após lerem as opções, eles selecionavam qual dos comportamentos a criança teria apresentado na situação estruturada (por exemplo: Situação 1 - Pede ajuda de adultos, tem-se como Opção: 1 -Tenta algumas vezes e ao não conseguir pede ajuda claramente com perguntas do tipo "Como eu faço para abrir?"; etc.).

Descrição em Áudio das Situações Estruturadas. Mídia CD contendo a descrição padronizada, em áudio, de cada situação estruturada,apresentada aos informantes no momento em que se solicitava a estimativa do desempenho da criança.

Roteiro das Situações Estruturadas. Texto com descrição detalhada do contexto das situações, participantes, falas e demandas que foram propostas às crianças em cada uma de cinco situações extraídas da Escala de Comportamentos Sociais para Pré-escolares (PKBSBR). Esse texto foi utilizado na condução das situações estruturadas como forma de garantir a padronização das falas e ações. As habilidades sociais convertidas em situações estruturadas foram: (1) Pede ajuda de adultos quando se machuca, (2) Segue instruções de adultos, (3) Defende seus próprios direitos, (4) Compartilha brinquedos e pertences e (5) Convida outras crianças para brincar.

Sistema de Categorias para Avaliação do Desempenho Social Infantil. Lista de comportamentos (e respectivas definições) possíveis de serem apresentados pelas crianças nas situações estruturadas e/ou mencionados nos relatos das informantes nas entrevistas, disponibilizada a juízes para a análise dos comportamentos apresentados pela criança e estimados pelos informantes.

Protocolo de Registro do Desempenho Social Infantil. Ficha entregue aos juízes para anotarem, após a análise da videogravação, quais comportamento foram apresentados pela criança em cada situação.

Protocolo da Estimativa dos Informantes. Ficha com transcrição literal das respostas dadas pela informante às questões abertas e fechadas, com espaço para a categorização, pelos juízes, dessas respostas nas opções do Sistema de Categorias para Avaliação do Desempenho Social Infantil.

Protocolo de Comparação entre Dados de Relato e de Observação. Tabela elaborada para organizar os dados de relatos de diferentes informantes e os de observação de comportamento das crianças. Apresentava colunas para que, em cada uma das cinco situações, fosse efetuado um registro das opções de comportamentos selecionadas por meio dos relatos em entrevistas das mães, das professoras e dos dados de observação do desempenho social da criança. 
Havia também colunas para registro da presença ou ausência de concordância entre os dados de relato (mãe ou professora) e observação.

Equipamentos e outros materiais. Foram utilizados: câmera filmadora para registro dos comportamentos em situação estruturada, um tripé para filmadora, fitas mini DV, um microcomputador, gravador, fones de ouvido e os programas estatísticos SPSS versão 15.0 e BioEstat versão 3.0. Durante a condução das situações estruturadas, foram empregados materiais lúdicos e objetos pertinentes à composição das situações.

\section{Procedimento de Coleta de Dados}

A exposição das crianças às situações estruturadas e as entrevistas com as informantes foram realizadas em uma clínica de Psicologia. Cada criança foi exposta a cinco situações estruturadas, organizadas em duas sessões (três situações em uma sessão e duas em outra), em dias diferentes para evitar o cansaço. Cada sessão foi integralmente videogravada para posterior análise dos desempenhos.

Após a coleta de dados com as crianças, as mães e as professoras foram entrevistadas individualmente, com base no Roteiro de Entrevista e adotando o CD de áudio com a descrição das situações. Quando se perguntava aos informantes o que a criança teria feito na situação, pediase a especificação de detalhes (comportamento vocal e motor). Depois era apresentada a Lista de opções de desempenho social infantil para informantes, pedindo-se que a entrevistada selecionasse a opção que melhor representava sua estimativa sobre o possível comportamento da criança e justificasse sua escolha por tal opção. Todas as entrevistas foram gravadas em áudio.

\section{Tratamento de Dados}

Cada um dos dois juízes, treinados e com nível de concordância de 85\% (estabelecido previamente como aceitável) com a pesquisadora, assistiu às filmagens e avaliou, individualmente, as vídeo gravações de metade das crianças, preenchendo o Protocolo de Registro do Desempenho Social Infantil com as categorias correspondentes aos comportamentos apresentados pela criança. Os juízes categorizaram os relatos dos informantes, registrando suas respostas no Protocolo de Registro de Relato dos Informantes sobre Desempenho Social das Crianças. As categorias foram convertidas em escala numérica (Apêndice 1) com variação em termos de competência social para cada categoria: -4 (Polo negativo máximo = compromete totalmente a competência social) à +4 (Polo positivo máximo $=$ contribui totalmente para a competência social).

Além disso, com a utilização do Protocolo de Comparação dos Dados de Relato e de Observação, a pesquisadora registrava a presença (1) ou ausência (0) de concordância entre os dados de relato e de observação, comparando-se convergências e divergências entre: relato de mãe versus relato de professora versus observação; (2) relato de mãe versus observação, (3) relato de professora versus observação e (4) relato de mãe versus relato de professora.

\section{Resultados}

As Figuras 1, 2, 3, 4 e 5 apresentam, no eixo das ordenadas, as opções de avaliação de competência social na escala de $-4 \mathrm{a}+4$ (números correspondentes ao valor de competência social atribuído às categorias comportamentais do Sistema). Já no eixo das abscissas, estão representadas as crianças por um número e com a sinalização de seu respectivo grupo.

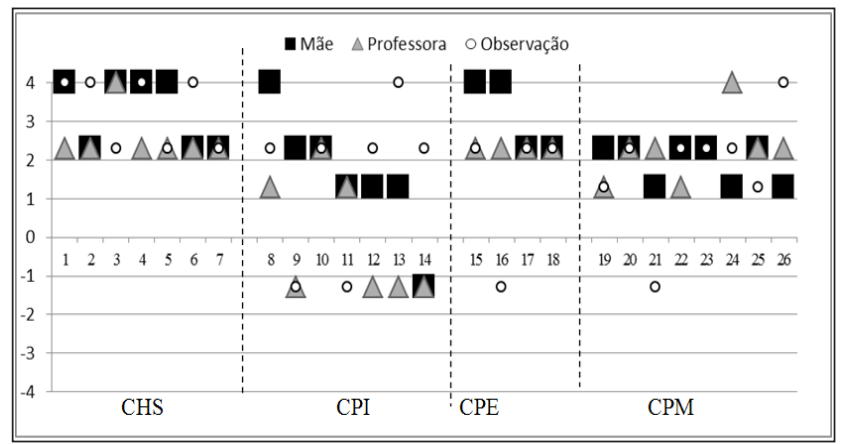

Figura 1. Distribuição das crianças nas opções de desempenho social infantil da Situação 1 (Pede ajuda de adultos quando necessário), de acordo com a estimativadas professoras, das mães e de observação em situações estruturadas.

Com base na Figura 1, pode-se observar que, na Situação 1 (Pede ajuda de adultos) a convergência entre os três tipos de avaliações foi a mais frequente, ocorrendo em cinco crianças, a maioria do grupo CPE. As convergências entre relato das mães e observação localizaram-se nos grupos CHS e CPM e entre relato das professoras e observação distribuiu-se igualmente entre os grupos. A convergência entre relatos concentrou-se nos grupos CHS e CPI. As divergências ocorreram mais no grupo CPI e, no geral, os relatos dos informantes subestimaram a competência social (C12, C13 e C14), enquanto as superestimações, na avaliação das mães, ocorreram para C9 e C16 e para ambas avaliadoras, no caso de $\mathrm{C} 21$.

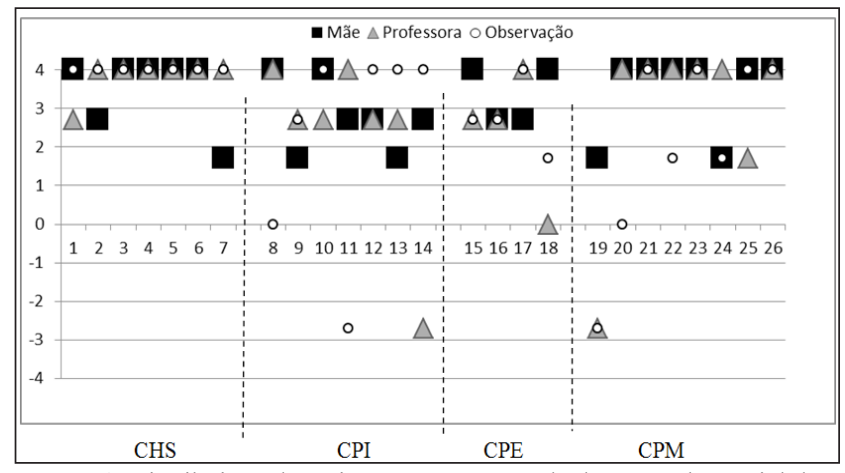

Figura 2. Distribuição das crianças nas opções de desempenho social da Situação 2 (Segue instruções de adultos), de acordo com a estimativa das professoras, das mães e de observação em situações estruturadas. 
Na Situação 2 (Segue instruções de adultos), como se observa na Figura 2, o maior número de convergências ocorreu entre as três avaliações, com maior concentração no grupo CHS. As convergências entre relato da professora e observação localizaram-se principalmente nos grupos CHS e CPE. Metade das convergências entre avaliação das mães e observação foi no grupo CPM. As convergências entre relatos distribuíram igualmente nos grupos CPI e CPM. Quanto às divergências, as mais altas foram observadas no CPI (subestimação - C14 e superestimação - C11 e C8), além de ocorrerem no grupo CPM para $\mathrm{C} 19$ e C20.

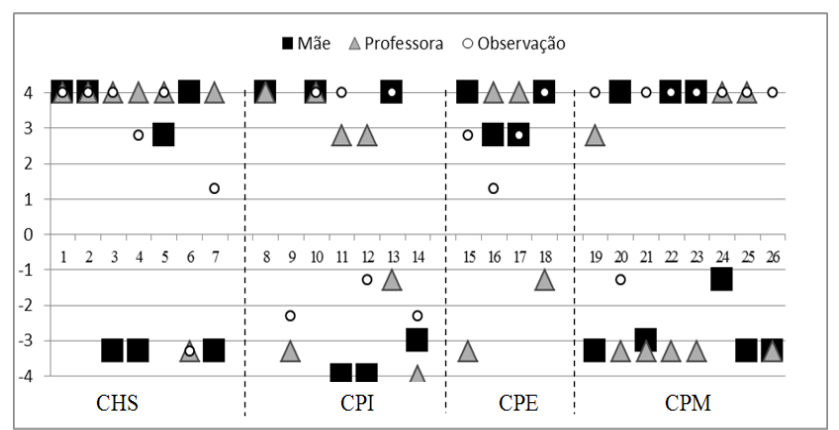

Figura 3. Distribuição das crianças nas opções de desempenho social da Situação 3 (Defende seus próprios direitos), de acordo com a estimativa das professoras, das mães e de observaçãoem situações estruturadas.

A Figura 3 mostra que na Situação 3 (Defende seus próprios direitos), as convergências concentram-se mais entre avaliação da professora e observação, principalmente no grupo CHS. As convergências entre as três avaliações foi menos frequente, concentrando-se no grupo CHS. A avaliação das mães foi mais convergente com a observação para o grupo CPE e CPM. Já na relação entre os dados de relato, houve apenas duas convergências. Para as divergências, foi observada uma alta frequência e intensidade de subestimação, concentrada no grupo CPM (C19, C21, C22, C23, C24, C25 e C26), mas em menor frequência para os grupos: CPI (C11 e C13), CPE (C15 e C18) e CHS (C3, C4 e C7). Já as superestimações foram mais raras nessa situação (C6, C12 e C20).

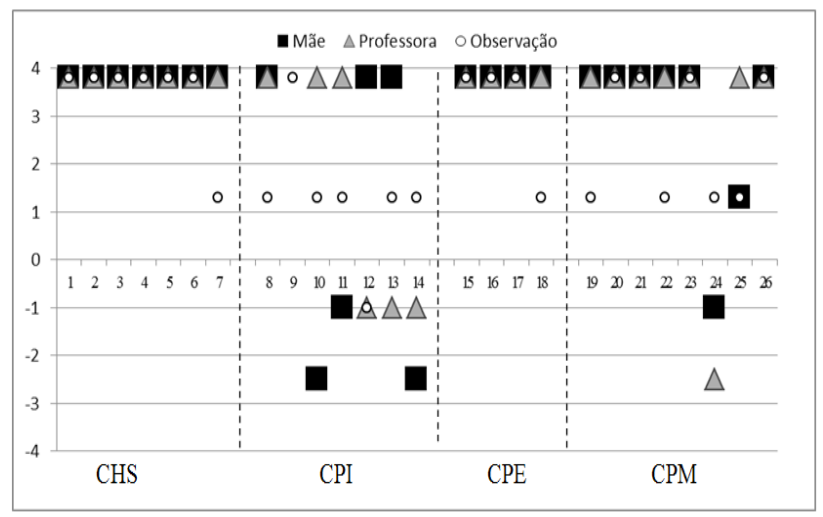

Figura 4. Distribuição das crianças nas opções de desempenho social da Situação 4 - (Compartilha brinquedos e pertences), de acordo com a estimativa das professoras, das mães e de observação em situações estruturadas.
Com base na Figura 4, verifica-se que, na Situação 4 (Compartilha brinquedos e pertences), o tipo de convergência mais frequente foi entre o relato de mãe e observação, concentrando-se no grupo CPM. As convergências entre avaliação de professoras e observação localizaram-se mais no grupo CPI. Já as convergências entre relato de professora e mães, essas ocorreram principalmente no grupo CHS. Houve apenas uma convergência entre os três tipos de avaliação que se localizou no grupo CPE. A análise das divergências indicou subestimações intensas distribuídas nos quatro grupos: $\mathrm{CPE}(\mathrm{C} 18), \mathrm{CHS}(\mathrm{C} 3), \mathrm{CPI}(\mathrm{C} 9$ e C11) e CPM (C26).

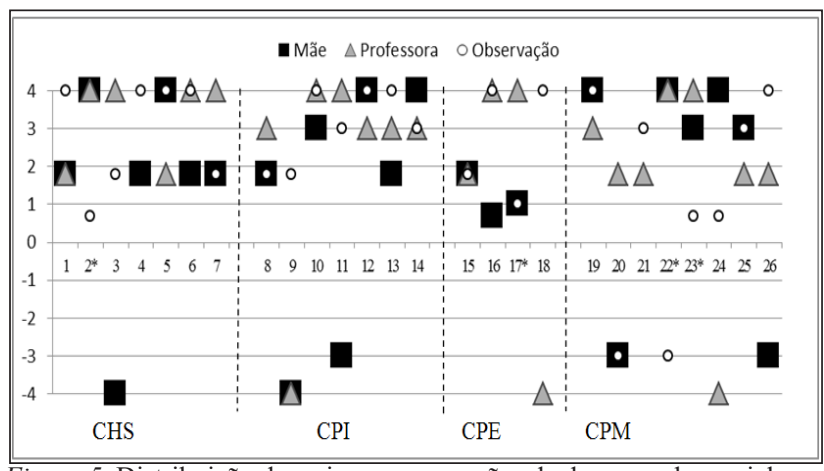

Figura 5. Distribuição das crianças nas opções de desempenho social da Situação 5 (Convida outras crianças para brincar), de acordo com a estimativa das professoras, das mães e de observação em situações estruturadas

Na Figura 5, observa-se que na Situação 5 (Convida outras crianças para brincar), houve uma alta frequência de convergência entre as três avaliações, localizadas principalmente no grupo CHS. Houve apenas uma convergência entre avaliação da professora e observação localizada no grupo CPI e uma entre a avaliação da mãe e a observação no grupo CPM, além de seis convergências entre os relatos concentradas no grupo CPM. Ao contrário do que ocorreu nas demais situações, foi observada uma alta frequência de superestimação dos avaliadores na maioria das crianças do grupo CPI (C8, C10, C11, C12 e 13). Contudo, as subestimações mais intensas também se concentraram principalmente nesse mesmo grupo (C10 e C14). No grupo $\mathrm{CPM}$, houve uma subestimação (C24).

De modo geral, houve uma menor proporção de convergências nas estimativas das crianças do grupo CPI. Com relação às divergências, os dados das Figuras 1, 2, 3, 4 e 5 totalizaram 150 ocorrências, sendo $57 \%$ do tipo subestimação, concentrada principalmente no grupo CPI (38 subestimações), enquanto as superestimações se concentraram principalmente no grupo CPM exceto na situação 3 , que apresentou maior frequência de alta subestimação (20). Na maioria das situações, tanto as subestimações como as superestimações foram medianas, exceto na situação 3 para a qual houve alta frequência de subestimações intensas.

Algumas crianças, principalmente dos grupos CPI e CPM, foram objeto de alta frequência de divergências, como: C11 - avaliação da mãe, em geral, subestimou o desempenho da criança; C12- subestimações e superestimações pela mãe; C13 - avaliações frequentes de subestimação do desempenho, principalmente pela professora; $\mathrm{C} 20$ - teve o desempenho 
superestimado de modo mínimo ou médio por ambas as avaliadoras; C26- desempenhos subestimados pela mãe e professora. Além dessas, C 18 do grupo CPE teve frequentes subestimações feitas pela professora.

Ao comparar as Figuras 1, 2, 3, 4 e 5 em termos das situações em que ocorreu convergência ou divergência para cada grupo, pode-se observar que em todas as situações estruturadas, as crianças do grupo CHS emitiram o comportamento-alvo esperado e foram avaliadas nas opções classificadas socialmente competente, o que foi estimado também pelos informantes, exceto um caso de superestimação na situação 2 e um de subestimação na situação 4, ambos na avaliação das mães. $\mathrm{Na}$ maior parte das situações (Figuras 1, 2 e 5), pode-se observar uma concentração dos três tipos de avaliação nas duas opções com as pontuações mais altas em termos de competência social.

\section{Discussão}

As análises individuais para cada situação mostraram que: (a) a maior frequência de convergências concentrou-se no grupo CHS; (b) as divergências no conjunto de dados foram a maior parte de subestimação, principalmente no grupo CPI, enquanto as superestimações se concentraram principalmente no grupo CPM, exceto para a Situação 3 (Defende seus próprios direitos) relacionada à assertividade, na qual a subestimação foi frequente e (c)a Situação 5 (Convida outras crianças para brincar) teve a maior frequência de convergências e a Situação 3 (Defende seus próprios direitos) teve a maior frequência de divergências, principalmente do tipo subestimação.

A alta frequência de subestimações na Situação 3 (Defende seus próprios direitos) pode indicar que os agentes de socialização (mãe e professora, nesse caso) parecem não estar atentos à importância desse comportamento social, o que se assemelha aos dados da literatura que afirmam que comportamentos assertivos são pouco valorizados e reconhecidos no ambiente social (Del Prette \& Del Prette, 2005; Dias, Del Prette, Del Prette Freitas, \& Magalhães, 2008). Ainda, comportamentos da classe de assertividade podem inclusive ser confundidos com agressividade por pais e professores e serem punidos. Investigações futuras poderiam verificar quais comportamentos assertivos e agressivos são mais frequentes em crianças consideradas com comportamentos-problema e como eles são consequenciados por pais e professores.

A utilização de fontes e procedimentos diversificados de avaliação no presente estudo pode trazer implicações para a clínica. Neste sentido, Conte e Regra (2000) destacam a importância e a necessidade desse tipo de avaliação na terapia infantil. De acordo com as autoras, a coleta de informações com pais e professores constitui-se procedimento central para se acessar os comportamentos das crianças, emitidos em contexto natural como família ou escola, bem como o possível julgamento enviesado ou falho dos pais e professores.

Ainda com relação ao contexto terapêutico, a identificação de subestimações e superestimações para cada criança, realizada no presente estudo pode trazer desdobramentos para intervenções. Uma possibilidade seria intervir junto a mães e professoras de crianças com comportamentosproblema que, tal como no presente estudo, tenham seu desempenho superestimado ou subestimado no sentido de se buscar novas maneiras de os agentes de socialização observarem e reagirem aos comportamentos das crianças. Um procedimento possível, a ser testado, seria a apresentação da filmagem dos desempenhos das crianças em situações estruturadas a pais e professores que poderiam avaliar se esse comportamento ocorre em sua casa, com qual frequência, sua adequação e como costumam reagir nessas situações (consequências fornecidas). Tal procedimento poderia contribuir para a avaliação de como as crianças se comportam nos diferentes contextos e a forma como os agentes de socialização consequenciam os comportamentos. A confiabilidade dos relatos poderia ser investigada com registros de comportamentos das crianças em situações naturais como escola e casa, permitindo constatar se possíveis divergências entre as avaliações seriam resultado de avaliações distorcidas ou realmente de fatores contextuais.

Uma limitação do estudo é o fato de a primeira autora ter desempenhado diferentes funções na condução da pesquisa e ter participado também das análises dos dados, ainda que tenha sido adotada a análise de dados por juízes externos para a minimização de possíveis vieses. Outras limitações referemse ao número reduzido da amostra e o não emparelhamento quanto a variáveis destacadas pela literatura como relevantes para problemas de comportamento, como sexo (Graminha, 1994; Marturano, Toller \& Elias, 2005), idade (Graminha, 1994) e nível socioeconômico (Qi \& Kaiser, 2003).

Futuros estudos poderiam ser desenvolvidos nas seguintes vertentes: análises mais detalhadas de subestimações e superestimações, identificando-se em que grupo se concentrou cada tipo de divergência e para qual avaliador, por meio de análises estatísticas; investigações de variáveis de procedimento e contextos que podem contribuir para melhora a estimativa das mães e professoras, como por exemplo, identificação, junto a mães e professoras, de situações antecedentes do cotidiano em que as crianças emitem dados comportamentos de classes de habilidades sociais, à semelhança do que fez Leme e Bolsoni-Silva (2010). Esse levantamento de situações antecedentes que costumam evocar as respostas das classes de habilidades sociais poderia servir de base para se planejar as situações estruturadas nessas intervenções.

\section{Considerações Finais}

O desenvolvimento do presente estudo tem implicações metodológicas para a elaboração e adoção de diferentes recursos de avaliação e para o uso combinado dos mesmos em futuras investigações. Pode também ter desdobramentos práticos para o campo das Habilidades Sociais e para a Avaliação Psicológica, além da Psicologia do Desenvolvimento.

Quanto a implicações práticas, é importante que se estimule pais e professores a atentarem mais às habilidades sociais e, então, consequenciarem positivamente essas repostas, aumentando a probabilidade dessas ocorrerem. Pais e professores, enquanto principais agentes de promoção de 
competência social, devem também ser instruídos quanto aos critérios de avaliação de desempenho social de seus filhos e alunos. Certamente, é desejável que esses agentes reconheçam e promovam comportamentos que atendam não somente aos critérios instrucionais, mas também éticos de competência social, conforme detalhados por Del Prette e Del Prette (2012). Assim, desde a infância, aumenta-se a probabilidade de trocas sociais pautadas nos critérios de competência social: consecução de objetivos pessoais, equidade de reforçadores aos envolvidos na interação, melhoria/manutenção das relações sociais e da autoestima, respeito aos direitos humanos (Del Prette \& Del Prette, 2001; 2005). Se atendidos esses critérios, haverá maior probabilidade de as crianças, e também os adultos, viverem em ambientes mais saudáveis, seja o escolar, seja o doméstico.

\section{Refereências}

American Psychiatric Association. (2002). Manual diagnóstico e estatístico de Transtornos Mentais: DSM-IV-TR (4 ${ }^{\mathrm{a}}$ ed., texto revisto). Porto Alegre: Artmed.

Bandeira, M. B., Barroso, S., Reis, F. V., Gaspar, T., \& Silva, M. (2004). Competência social de psicóticos: O comportamento de alternância da fala em situações de fazer e receber críticas. Estudos de Psicologia (Campinas) 21, 143-159.

Bandeira, M. B., Barroso, S. M., \& Reis, F. V. (2004). Desempenho social de psicóticos em função do comportamento do interlocutor em interações sociais. Interação em Psicologia, 8, 247-259.

Barreto, S. O., Freitas, L. C., \& Del Prette, Z. A. P. (2011). Habilidades sociais na comorbidade entre dificuldade de aprendizagem e problemas de comportamento: Uma avaliação multimodal. PSICO (RS), 43, 503-510.

Bolsoni-Silva, A. T., Marturano, E. M., \& Manfrinato, J. W. S. (2005). Mães avaliam comportamentos socialmente "desejados" e "indesejados" de pré-escolares. Psicologia em estudo, 10, 245-252.

Bolsoni-Silva, A. T., Marturano, E. M., Pereira, V. A., \& Manfrinato, J. W. S. (2006). Habilidades sociais e problemas de comportamento de pré-escolares: Comparando avaliações de mães e de professoras. Psicologia: Reflexão e Crítica, 19 (2), 460-469.

Conte, F. C. S., \& Regra, J. A. G. (2000). A psicoterapia comportamental infantil: Novos aspectos. In E. F. M. Silvares (Org.). Estudos de caso em psicologia clínica comportamental infantil (vol. 2, pp. 79-136). Campinas: Papirus.

Del Prette, A., \& Pereira, C. S. (2008). Procedimentos de observação em situações estruturadas para avaliação de habilidades sociais profissionais de adolescentes. Psicolog, 1(1), 55-67.

Del Prette, A., \& Del Prette, Z. A. P. (2001). Psicologia das relações interpessoais: Vivências para o trabalho em grupo. Petrópolis: Vozes.

Del Prette, Z. A. P., \& Del Prette, A. (2005a). Psicologia das habilidades sociais na infância: Teoria e prática. Petrópolis: Vozes.

Del Prette, Z. A. P. \& Del Prette, A. (2005b). Sistema Multimídia de Habilidades Sociais para Crianças (SMHSC-Del-Prette): Manual. São Paulo: Casa do Psicólogo
Del Prette, Z. A. P., \& Del Prette, A. (2006). Avaliação multimodal de habilidades sociais em crianças: Procedimentos, instrumentos e indicadores. In M. Bandeira, Z. A. P. Del Prette \& A. Del Prette (Orgs.), Estudos sobre Habilidades Sociais e Relacionamento Interpessoal (pp. 47-68). São Paulo: Casa do Psicólogo.

Del Prette, Z. A. P., Monjas-Casares, M. I., \& Caballo, V. E. (2006). La evaluación del repertorio de las habilidades sociales en ninõs. In V. E. Caballo (Org.), Manual para la evaluación clínica de los transtornos psicológicos: Transtornos de la edad adulta e informes psicológicos (pp. 371-399). Madrid: Pirámide.

Del Prette, Z. A. P., \& Del Prette, A. (2009) Avaliação de habilidades sociais: bases conceituais, instrumentos e procedimentos. In Z. A. P. Del Prette \& A. Del Prette (Orgs.), Psicologia das Habilidades Sociais: diversidade teórica e suas implicações (pp.189-231). Petrópolis: Vozes.

Del Prette, Z. A. P., \& Del Prette, A. (2012). Social skills and behavior analysis: Historical proximity and new issues. Perspectivas em Análise do Comportamento, 1, 104-115.

Del Prette, Z. A. P., Del Prette, A., de Oliviera, L. A., Gresham, F. M., \& Vance, M. J. (2012). Role of social performance in predicting learning problems: Prediction of risk using logistic regression analysis. School Psychology International Journal, 2, 615-630.

Dias, T. P., Freitas, L. C., Del Prette, Z. A. P., \& Del Prette, A. (2011). Validação da Escala de Comportamentos Sociais de Pré-escolares para o Brasil. Psicologia em Estudo 16, 447-455.

Dias, T. P.; Del Prette, A., Del Prette, Z. A. P., Freitas, L.C. \& Magalhães, T. (2008). Validade social das habilidades sociais sob a perspectiva do professor: Replicação com amostra ampliada. Em M. A. Almeida, E. G. Mendes, M. C. P.I. Hayashi. (Orgs.), Temas em Educação Especial: Múltiplos olhares (pp. 347-355.) 1ed.São Carlos.

Feitosa, F. B. (2003). Relação família-escola: Como pais e professores avaliam e reagem ao repertório social de crianças com e sem dificuldades de aprendizagem. Dissertação de mestrado não publicada, Curso de Pós Graduação em Educação Especial, Universidade Federal de São Carlos, São Carlos, SP.

Ferreira, B. C., Del Prette, Z. A. P., \& Lopes, D. C. (2009). Habilidades empáticas de crianças videntes e cegas e a possível influência de variáveis sociodemográficas. Interação em Psicologia, 13, 49-58.

Freitas, L. C., \& Del Prette, Z. A. P. (2010). Comparando autoavaliação e avaliação de professores sobre as habilidades sociais de crianças com deficiência mental. Interpersona, 4, 183-193.

Garcia-Serpa, F. A., Del Prette, Z. A. P., \& Del Prette, A. (2006). Meninos pré-escolares empáticos e não-empáticos: Empatia e procedimentos educativos dos pais. Revista Interamericana de Psicologia, 40, 77-88.

Graminha, S. S. V. (1994). Problemas emocionais/comportamentais em uma amostra de escolares: Incidência em função do sexo e idade. Psico, 25, 49-74.

Gresham, F. M., \& Elliott, S.N. (2008). Social skills improvement system: Rating scales. Bloomington: Pearson Assessments.

Gresham, F. M. (2009). Análise do comportamento aplicada às habilidades sociais. In A. Del Prette \& Z. A. P. Del Prette (Orgs.), Psicologia das habilidades sociais: Diversidade teórica e suas implicações (pp. 17-66). Petrópolis: Vozes. 
Hinshaw, S.P., Han, S.S., Erhardt, D., \& Huber, A. (1992). Internalizing and externalizing behavior problems in preschool children: correspondence among parent and teacher ratings and behavior observations. Journal of Clinical Child \& Adolescent Psychology, 21(2). Retirado em 06/03/2008 na Web of Science: http://www apps.isiknowledge.com/

Leme, V. B. R., \& Bolsoni-Silva, A. T. (2010). Investigando as habilidades sociais de pré-escolares com problemas de comportamento. In Ana Cláudia Bortolozzi Maia; Tânia Gracy Martins do Valle (Org.), Aprendizagem e comportamento humano 1 (pp 197-221) São Paulo: Cultura Acadêmica.

Leme, V. B. R., Bolsoni-Silva, A. T. (2010). Habilidades sociais educativas parentais e comportamentos de pré-escolares. Estudos de Psicologia (Natal), 15, 161-173.

Marturano, E. M., Toller, G. P., \& Elias, L. C. S. (2005). Gênero, adversidade e problemas socioemocionais associados à queixa escolar. Estudos de Psicologia, 22, 371-380.

Merrell. K. W. (2002). Preschool and kindergarten behavior scales (2nd Ed). Austin, TX: PRO-ED

Organização Mundial de Saúde .(1993). Classificação de Transtornos Mentais e de Comportamento da CID-10; Descrições Clínicas e Diretrizes Diagnósticas. Porto Alegre: Artes Médicas.
Pavarino, M. G. P., Del Prette, A., \& Del Prette, Z.A.P (2005). Agressividade e empatia na infância: Um estudo correlacional com pré-escolares. Interação em Psicologia, 9, 215-225.

Qi, C. H., \& Kaiser, A. P. (2003). Behavior problems of preschool children from low income families: Review of the literature. Topics in Early Childhood Special Education, 23, 188-216.

Silva, A. T. B. (2000). Problemas de comportamento e comportamentos socialmente adequados: Sua relação som as habilidades sociais educativas de pais. Dissertação de Mestrado não publicada, Curso de Pós-Graduação em Educação Especial, Universidade Federal de São Carlos, SP.

Winsler, A., \& Wallace, G.L. (2002). Behavior problems and social skills in preschool children: parent-teacher agreement and relations with classroom observations. Early Education and Development, 13(1). Retirado em 06/03/2008 na Web of Science: http://www.apps.isiknowledge.com/.

Recebido em 02.08.2013

Primeira decisão editorial em 16.06.2015

Versão final em 16.06.2015

Aceito em 17.08.2015 


\section{APÊNDICE}

Resumo das opções do Sistema de Categorias para Avaliação de Desempenho Social Infantil e suas respectivas pontuações atribuídas por juizes

\begin{tabular}{|c|c|c|c|}
\hline Situação & $\begin{array}{l}\text { Classificação } \\
\text { Dicotômica }\end{array}$ & Opções de Comportamento & Escore \\
\hline \multirow{5}{*}{$\begin{array}{l}\text { 1. Pede ajuda de adultos quando } \\
\text { necessário }\end{array}$} & \multirow{3}{*}{ Competente } & 1. Pede explicitamente ajuda & 4 \\
\hline & & 2. Pede implicitamente ajuda & 2,3 \\
\hline & & 3. Pede implicitamente ajuda com atraso & 1,3 \\
\hline & \multirow{2}{*}{ Não competente } & 4. Faz tentativas independentes... & $-1,3$ \\
\hline & & 5. Faz tentativas independentes e emite incompatíveis & -4 \\
\hline \multirow{6}{*}{ 2. Seguir instrução de adultos } & \multirow{3}{*}{ Competente } & $\begin{array}{l}\text { 1. Segue a instrução e emite comportamentos sociais compatíveis } \\
\text { com habilidades sociais. }\end{array}$ & 4 \\
\hline & & 2. Segue a instrução recebida. & 2,7 \\
\hline & & $\begin{array}{l}\text { 3. Apresenta outros comportamentos não especificados pela } \\
\text { instrução, mas que têm a função de disponibilizar material. }\end{array}$ & 1,7 \\
\hline & Neutro & 4. Estabelece interação com o colega não especificada na instrução & 0 \\
\hline & \multirow[b]{2}{*}{ Não competente } & 5. Permanece sob controle de outros aspectos da situação & $-2,7$ \\
\hline & & $\begin{array}{l}\text { 6. Apresenta comportamentos não especificados pela instrução } \\
\text { indicativos de desconforto }\end{array}$ & $-3,8$ \\
\hline \multirow{8}{*}{$\begin{array}{l}\text { 3. Defender seus próprios } \\
\text { direitos }\end{array}$} & \multirow{3}{*}{ Competente } & 1. Argumenta em defesa dos próprios direitos & 4 \\
\hline & & 2. Afirma que ganhou & 2,8 \\
\hline & & 3. Hesita em defender seu direito & 1,3 \\
\hline & \multirow{5}{*}{ Não competente } & 4. Pára de reivindicar por seu direito & $-1,3$ \\
\hline & & 5. Expressa incerteza sobre a violação de seu direito & $-2,3$ \\
\hline & & 6. Mantém-se alheio à violação do direito & -3 \\
\hline & & $\begin{array}{l}\text { 7. Defende seu direito, e emite comportamentos sociais } \\
\text { incompatíveis com habilidades sociais }\end{array}$ & $-3,3$ \\
\hline & & $\begin{array}{l}\text { 8. Mantém-se calado e apresenta comportamentos indicativos de } \\
\text { sentimentos negativos }\end{array}$ & -4 \\
\hline \multirow{7}{*}{$\begin{array}{l}\text { 4. Compartilhar brinquedos e } \\
\text { pertences }\end{array}$} & \multirow{4}{*}{ Competente } & $\begin{array}{l}\text { 1. Disponibiliza material e emite compatíveis com habilidades } \\
\text { sociais }\end{array}$ & 4 \\
\hline & & 2. Disponibiliza prontamente o material em silêncio & 3 \\
\hline & & 3. Disponibiliza o material com pequeno atraso & 1,8 \\
\hline & & 4. Disponibiliza o material com sinais de resistência & 0,7 \\
\hline & \multirow{3}{*}{ Não competente } & 5. Mantém-se alheio à solicitação do colega & -2 \\
\hline & & $\begin{array}{l}\text { 6. Disponibiliza material e emite comportamentos sociais } \\
\text { incompatíveis com habilidades sociais }\end{array}$ & -3 \\
\hline & & 7. Recusa agressivamente a solicitação & -4 \\
\hline \multirow{6}{*}{$\begin{array}{l}\text { 5. Convidar outras crianças } \\
\text { para brincar }\end{array}$} & \multirow{3}{*}{ Competente } & $\begin{array}{l}\text { 1. Convida explicitamente para brincar e emite compatíveis com } \\
\text { habilidades sociais }\end{array}$ & 3,8 \\
\hline & & $\begin{array}{l}\text { 2. Estabelece condições explícitas para introduzir o colega na } \\
\text { brincadeira }\end{array}$ & 3,8 \\
\hline & & $\begin{array}{l}\text { 3. Estabelece condição simples para introduzir colega na } \\
\text { brincadeira }\end{array}$ & 1,3 \\
\hline & \multirow{3}{*}{ Não Competente } & $\begin{array}{l}\text { 4. Estabelece condição insuficiente para introduzir o colega na } \\
\text { brincadeira }\end{array}$ & -1 \\
\hline & & 5. Mantém-se sob controle da atividade individual & $-2,5$ \\
\hline & & 6. Faz provocações ao colega & -4 \\
\hline
\end{tabular}

